\title{
Lactobacillus sakei suppresses collagen-induced arthritis and modulates the differentiation of T helper 17 cells and regulatory $B$ cells
}

Jooyeon Jhun ${ }^{1,2+}{ }^{\text {, Hong Ki Min }}{ }^{3 \dagger}$, Jaeyoon Ryu ${ }^{1,2}$, Seon-Yeong Lee ${ }^{1,2}$, Jun-Geol Ryu ${ }^{1,2}$, Jeong Won Choi ${ }^{1,2}$, Hyun Sik Na,2, Seung Yoon Lee ${ }^{1,2}$, Yunju Jung 4,5, Sang-Jun Park' ${ }^{5}$ Myeong Soo Park ${ }^{4}$, Bin Kwon ${ }^{4}$, Geun Eog Ji, ${ }^{4,5}$, Mi-La Cho ${ }^{1,2,6^{*}+} \bigcirc$ and Sung-Hwan Park ${ }^{7 *+}$

\begin{abstract}
Background: To evaluate the immunomodulatory effect of Lactobacillus sakei in a mouse model of rheumatoid arthritis (RA) and in human immune cells.

Methods: We evaluated whether L. sakei reduced the severity of collagen-induced arthritis $(C I A)$ and modulated interleukin (IL)-17 and IL-10 levels, as well as whether it affected the differentiation of CD4 ${ }^{+} \mathrm{T}$ cells and regulatory B cells. We evaluated osteoclastogenesis after culturing bone marrow-derived mononuclear cells with L. sakei.

Results: The differentiation of T helper 17 cells and the serum level of IL-17 were suppressed by L. sakei in both human peripheral blood mononuclear cells and mouse splenocytes. The serum level of IL-10 was significantly increased in the L. sakei-treated group, whereas the regulatory T cell population was unchanged. The population of regulatory B cells significantly increased the in L. sakei-treated group. Oral administration of $L$. sakei reduced the arthritis incidence and score in mice with CIA. Finally, osteoclastogenesis and the mRNA levels of osteoclast-related genes were suppressed in the L. sakei-treated group.
\end{abstract}

Conclusion: L. sakei exerted an anti-inflammatory effect in an animal model of RA, regulated Th17 and regulatory B cell differentiation, and suppressed osteoclastogenesis. Our findings suggest that $L$. sakei has therapeutic potential for RA.

Keywords: Rheumatoid arthritis, Microbiome, Lactobacillus sakei, T helper 17 cell, Regulatory B cell

*Correspondence: iammila@catholic.ac.kr; rapark@catholic.ac.kr †Jooyeon Jhun and Hong Ki Min contributed equally to this work ${ }^{\dagger} \mathrm{Mi}-\mathrm{La}$ Cho and Sung-Hwan Park contributed equally to this work ${ }^{1}$ Rheumatism Research Center, Catholic Research Institute of Medical Science, College of Medicine, The Catholic University of Korea, Seoul 06591, South Korea

${ }^{7}$ Devision of Rheumatology, Department of Internal Medicine, Seoul St. Mary's Hospital, College of Medicine, The Catholic University of Korea, Seoul, Republic of Korea

Full list of author information is available at the end of the article

\section{Background}

Rheumatoid arthritis (RA) is a chronic destructive autoimmune-mediated arthritis. The prevalence of RA ranges from $0.1 \%$ to $5 \%$, depending on ethnicity and sex $[1,2]$. Treatments target the attenuation of arthralgia, as well as the suppression of joint destruction, which is irreversible and reduces the quality of life in affected patients. Multiple factors contribute to the development and progression of RA [3]. The interaction between the host and the microbiota is a key

(c) The Author(s) 2020. This article is licensed under a Creative Commons Attribution 4.0 International License, which permits use, sharing, adaptation, distribution and reproduction in any medium or format, as long as you give appropriate credit to the original author(s) and the source, provide a link to the Creative Commons licence, and indicate if changes were made. The images or other third party material in this article are included in the article's Creative Commons licence, unless indicated otherwise in a credit line to the material. If material is not included in the article's Creative Commons licence and your intended use is not permitted by statutory regulation or exceeds the permitted use, you will need to obtain permission directly from the copyright holder. To view a copy of this licence, visit http://creativeco mmons.org/licenses/by/4.0/. The Creative Commons Public Domain Dedication waiver (http://creativecommons.org/publicdomain/ zero/1.0/) applies to the data made available in this article, unless otherwise stated in a credit line to the data. 
modulator of the immune response and may contribute to autoimmune diseases, including RA [4]. The first evidence of a role for the microbiome in the pathogenesis of RA involved the observation of a higher frequency of Porphyromonas gingivalis (the etiologic agent of periodontitis) in patients with RA, compared with healthy controls [5]. Microbes reside at various body sites, particularly those exposed to the external environment (e.g., oral cavity, respiratory tract, and gastrointestinal tract). Approximately 100 trillion microbes reside in the human body, primarily in the gastrointestinal tract [4]. Dysbiosis in patients with RA, as well as following an inflammatory response in the gastrointestinal tract, is a key immunologic mechanism that contributes to the pathogenesis of RA [6, 7]. Therefore, controlling the gastrointestinal tract microbiome via oral administration of probiotics has therapeutic potential for RA. However, oral probiotics reportedly have minimal clinical efficacy in patients with RA [8]; notably, the prior study was limited by its small sample size and the use of various strains and quantities of probiotics. Few studies have demonstrated the therapeutic potential of probiotics in animal models of RA [9-11].

The genus Lactobacillus is an important component of the microbiomes of the human gastrointestinal tract and urinary tract. Lactobacillus sakei is typically found in cooked ham and inhibits pathogenic microbes such as Escherichia coli $\mathrm{O} 157: \mathrm{H7}$ and Listeria monocytogenes [12]. In a mouse model, oral administration of $L$. sakei attenuated colitis and reduced the expression of proinflammatory cytokines [13]. Furthermore, L. sakei has been shown to ameliorate obesity and reduce the levels of biomarkers of obesity (e.g., leptin) in mice [14], and it can suppress pathologic bacterium, Corynebacterium tuberculostearicum, which induces chronic rhinosinusitis in human [15]. L. sakei is widely found in fermented food such as kimchi, yogurt, and cheese [14, 16] and commonly used for meat preservation [17], which makes feasible to translate result of animal study into human application (translation of T1 research to T2 research). Results from the preclinical animal study can suggest the basic mechanism of $L$. sakei how they exert anti-inflammatory effects and encourage future clinical trials for applying $L$. sakei to real patients. Furthermore, common food sources of $L$. sakei increase the possibility to apply L. sakei in human subjects. The composition and diversity of gut microbiome differs depending on the immune status, and concomitant anti-rheumatic medication such as methotrexate could alter composition of microbiome and its influence on functional potency [18, 19]. L. sakei has clear anti-inflammatory activity, but its effect on RA is unclear. In addition, the anti-inflammatory potency of L. sakei from healthy and RA patients may differ.
A variety of immune cells and proinflammatory cytokines play important roles in the pathogenesis of RA [20]. T helper 17 cells (Th17) are implicated in several inflammatory and immune-mediated diseases, including RA; these cells produce interleukin (IL)-17 [21], which promotes synovitis, contributes to joint destruction, and augments osteoclastogenesis. Therefore, inhibition of IL-17 is a goal in the treatment of chronic inflammatory diseases, including RA [21, 22]. IL-10 is a key anti-inflammatory/immunomodulatory cytokine [23] produced by various immune cells including regulatory $\mathrm{T}$ cells (Tregs), macrophages, dendritic cells, and B cells. B cells are the progenitors of plasma cells, and B/plasma cells mediate RA by producing autoantibodies. However, B cells can also modulate immunity by producing anti- and pro-inflammatory cytokines [24]. Regulatory B cells (Bregs) secrete IL-10, transforming growth factor- $\beta$, and IL-35; moreover, they suppress the differentiation of proinflammatory lymphocytes, including Th17 and cytotoxic $\mathrm{CD}^{+} \mathrm{T}$ cells [25]. The numbers and activities of IL-10-producing Bregs are reduced in patients with RA [26]. Several animal models for RA have been established, and collagen-induced arthritis (CIA) model resembles RA symptom by inducing autoantibody and Th17 polarization [27]. CIA model was suitable to evaluate immune response of $L$. sakei on $\mathrm{T}$ cell and $\mathrm{B}$ cell response.

In this in vitro study, we evaluated the immunologic responses to $L$. sakei by human and animal cells. Specifically, we assessed the serum levels of cytokines, as well as the differentiation of $\mathrm{T}$ and $\mathrm{B}$ lymphocytes and osteoclasts. Furthermore, we analyzed the effects of $L$. sakei on collagen-induced arthritis (CIA) by administrating L. sakei extracted from healthy control and RA patient.

\section{Methods \\ Animals}

Seven-week-old male DBA/1 J mice (Orient Bio, Gyeonggi-do, Republic of Korea) were maintained under specific pathogen-free conditions and provided standard laboratory mouse chow (Ralston Purina, St. Louis, MO, USA) and water ad libitum. The mice were housed at five per cage in a room maintained under controlled temperature $\left(21-22{ }^{\circ} \mathrm{C}\right)$ and lighting $(12 / 12 \mathrm{~h}$ light/dark cycle) conditions. All experimental procedures were approved by the Institutional Animal Care and Use Committee of the School of Medicine and the Animal Research Ethics Committee of the Catholic University of Korea; the procedures complied with the Laboratory Animals Welfare Act, in accordance with the Guide for the Care and Use of Laboratory Animals. 


\section{Induction and treatment of arthritis}

To induce CIA in DBA/1 J mice, chicken type II collagen $(4 \mathrm{mg} / \mathrm{mL})$ was dissolved overnight in $0.1 \mathrm{~N}$ acetic acid with gentle rotation at $4{ }^{\circ} \mathrm{C}$. DBA/1 J mice were injected intradermally at the base of the tail with $100 \mu \mathrm{g}$ of chicken type II collagen; an emulsion of Freund's adjuvant (Difco, Detroit, MI, USA) was administered to the hind legs of the mice as a booster injection. To assess the effects of $L$. sakei on the severity of CIA, DBA $/ 1 \mathrm{~J}$ mice received $50 \mathrm{mg} / \mathrm{kg} \mathrm{L}$. sakei in saline, or vehicle alone, via oral gavage six times per week for 7 weeks; this treatment began on day 21 after the primary immunization.

\section{Clinical assessment of arthritis}

The severity of arthritis was evaluated by three independent observers. The mice were observed twice weekly to determine the onset and severity of joint inflammation for up to 7 weeks after the primary immunization. The severity of arthritis was assessed on a scale of $0-4$, based on the following criteria [28]: $0=$ no edema or swelling; $1=$ slight edema, with erythema limited to the foot or ankle; $2=$ slight edema, with erythema from the ankle to the tarsal bone; $3=$ moderate edema, with erythema from the ankle to the tarsal bone; and $4=$ severe edema, with erythema from the ankle to the entire leg. The arthritis score of each mouse was calculated as the sum of the scores of the four limbs; the highest possible arthritis score for each mouse was 16 . The mean arthritis index was used to compare the scores of the control and experimental groups.

\section{Histological analysis}

Joint tissues were fixed in $10 \%(\mathrm{v} / \mathrm{v})$ neutral-buffered formalin, decalcified in a histological decalcifying agent (Calci-Clear Rapid; National Diagnostics, Atlanta, GA, USA), embedded in paraffin, and cut into $5-\mu \mathrm{m}$-thick sections. The sections were stained with hematoxylin and eosin, as well as Safranin O, to detect proteoglycans. Inflammation was scored using the following criteria: $0=$ no inflammation; $1=$ slight thickening of the lining, or infiltration of some cells into the underlying layer; $2=$ slight thickening of the lining, with infiltration of some cells into the underlying layer; $3=$ thickening of the lining, with influx of cells into the underlying layer and cells evident in the synovial space; and $4=$ extensive infiltration of the synovium by inflammatory cells. Cartilage damage was evaluated by staining with Safranin O and toluidine blue, and the extent of damage was scored as follows: $0=$ no destruction; $1=$ minimal erosion (limited to single spots); $2=$ slight-to-moderate erosion in a limited area; $3=$ more extensive erosion; and $4=$ general destruction.

\section{Immunohistopathological analysis of arthritis}

Joint tissue was first incubated with primary antibodies against tumor necrosis factor- $\alpha$, IL- $1 \beta$ (R\&D Systems, Minneapolis, MN, USA),, IL-6(R\&D Systems),, and IL-17 (R\&D Systems) overnight at $4{ }^{\circ} \mathrm{C}$. Samples were incubated with a biotinylated secondary antibody, followed by incubation with a streptavidin-peroxidase complex for $1 \mathrm{~h}$. Samples were then developed using chromogen 3,3'-diaminobenzidine (Thermo Scientific, Rockford, IL,USA). The sections were examined under a photomicroscope (Olympus, Tokyo, Japan). The number of positive cells was counted using Adobe Photoshop software (Adobe, USA) on high-power digital image (magnification: 400). Positive cells were enumerated visually by three individuals, and the mean values were calculated.

\section{Enzyme-linked immunosorbent assay}

The IL-17 and IL-10 concentrations in the supernatants of cultures of human cells were measured by sandwich enzyme-linked immunosorbent assay (ELISA) (R\&D Systems). The absorbance at $405 \mathrm{~nm}$ was determined using an ELISA microplate reader (Molecular Devices, Sunnyvale, CA, USA).

\section{Isolation and stimulation of splenocytes}

Splenocytes were prepared from the spleens of normal C57BL6 mice. Splenocytes were maintained in Roswell Park Memorial Institute (RPMI)-1640 medium supplemented with $5 \%$ fetal bovine serum (Gibco, Grand Island, NY, USA) before stimulation with plate-bound anti-CD3 $(0.5 \mu \mathrm{g} / \mathrm{mL})$ for 3 days; they were then subjected to flow cytometry analysis.

\section{Isolation and stimulation of peripheral blood mononuclear cells}

Peripheral blood mononuclear cells (PBMCs) were prepared from heparinized blood by standard FicollPaque density gradient centrifugation (GE Healthcare Biosciences, Uppsala, Sweden). Cells were cultured in RPMI-1640 medium (Gibco BRL, Carlsbad, CA, USA) containing penicillin $(100 \mathrm{U} / \mathrm{mL})$, streptomycin $(100 \mu \mathrm{g} /$ $\mathrm{mL}$ ), and $10 \%$ fetal bovine serum (Gibco BRL) that had been inactivated by heating to $55^{\circ} \mathrm{C}$ for $30 \mathrm{~min}$. Suspensions of both cell types were dispensed into 48-well plates (Nunc, Rosklide, Denmark). PBMCs were incubated with plate bound anti-CD3 $(0.5 \mu \mathrm{g} / \mathrm{mL})$ or lipopolysaccharide $100 \mathrm{ng} / \mathrm{mL}$ for 3 days. 


\section{Preparation of bacteria}

Patients with RA fulfilled the 2010 American College of Rheumatology and European League Against Rheumatism classification criteria [29]. Bacterial genomic DNA was isolated from fecal samples of RA patients (RH1114) and healthy normal subjects (RH1117). The study design was approved by the Institutional Review Board of Seoul St. Mary's Hospital, The Catholic University of Korea (approval ID: KC17TNSI0570). Written informed consents were obtained from all study participants.

$50 \mu \mathrm{L}$ of each bacterium was inoculated to $5 \mathrm{~L}$ cMRS liquid medium and incubated for $20 \mathrm{~h}$ at $37{ }^{\circ} \mathrm{C}$. After incubation, in order to remove the medium component, the supernatant of the medium was discarded by centrifugation (High Speed Centrifuge, 2236HR, Korea) at $20^{\circ} \mathrm{C}$ and $7000 \mathrm{rpm}$ with phosphate buffered saline (PBS) washing, twice. The washed bacterial cells were powdered by drying the remaining medium components at $36{ }^{\circ} \mathrm{C}, 2000 \mathrm{rpm}$ for $24 \mathrm{~h}$ using Scanvac Speed Vacuum Concentrator (Labogene Aps, Lillerød, Denmark). The powdered bacterial cells were heat-inactivated by heating at $80{ }^{\circ} \mathrm{C}$ for $30 \mathrm{~min}$. All bacteria used in this study were isolated from healthy subjects and patients with RA.

\section{Flow cytometry}

Levels of cytokines and transcription factors were assessed by intracellular staining using anti-IL-17-FITC, anti-Foxp3-FITC, and anti-Foxp3-PE antibodies (all from eBioscience, San Diego, CA, USA). Cells were stimulated with phorbol myristate acetate and ionomycin with the addition of GolgiStop for $4 \mathrm{~h}$. Cultured cells were surface labeled for $30 \mathrm{~min}$ and permeabilized with Cytofix/ Cytoperm solution (BD Pharmingen, Heidelberg, Germany). Cells were intracellularly stained with fluorescent antibodies and subjected to flow cytometry (FACSCalibur; BD Biosciences, Franklin Lakes, NJ, USA). Events were collected and analyzed using FlowJo software (Tree Star, Ashland, OR, USA).

\section{In vitro osteoclastogenesis and tartrate-resistant acid phosphatase staining}

Bone marrow cells from mouse femurs were cultured in alpha-minimal essential medium (Invitrogen, Carlsbad, CA, USA) containing antibiotics and 10\% heat-inactivated fetal bovine serum to separate floating and adherent cells. Nonadherent cells were removed by washing with media, and preosteoclasts were cultured in the presence of $10 \mathrm{ng} / \mathrm{mL}$ macrophage colony-stimulating factor, $100 \mathrm{ng} / \mathrm{mL}$ receptor activator of nuclear factor kappa-B (RANK) ligand (RANKL) (PeptoTech, London, UK), and L. sakei for 4 days to generate osteoclasts. The medium was changed every 2 days. Osteoclasts were generated after 8-10 days.

\section{TRAP staining}

A commercial TRAP kit (Sigma-Aldrich) was used according to the manufacturer's instructions; however, counterstaining with hematoxylin was not performed. TRAP-positive multinuclear cells (MNCs) containing three or more nuclei were counted as osteoclasts.

\section{Real-time polymerase chain reaction}

Polymerase chain reaction was performed using a Light Cycler 2.0 instrument (Roche Diagnostics, Mannheim, Germany) with software version 4.0. All reactions were performed using Light Cycler Fast Start DNA Master SYBR Green I (TaKaRa, Shiga, Japan), in accordance with the manufacturer's instructions. The following primers were used: TRAP, 5'-TCC TGG CTC AAA AAG CAG TT-3' (sense) and 5'-ACA TAG CCC ACA CCG TTC TC-3' (antisense); calcitonin receptor, 5'-CGG ACT TTG ACA CAG AA-3' (sense) and 5'-AGC AAT CGA CAA GGA GT-3' (antisense); integrin b3, 5' ${ }^{\prime}$ CTG TGG GCT TTA AGG ACA GC-3' (sense) and 5'-GAG GGT CGG TAA TCC TC-3' (antisense); cathepsin K, 5'-CAG AGG TGT GTA CTA TG-3' (sense) and 5'-GCG TTG TTC TTA TTC CGA GC-3' (antisense); RIPK1, 5'-CTG TTC CCT GTG CCC AAT AA-3' (sense) and 5'-ATG ACT CTG AAG CTG TCC TTT C-3' (antisense); and RIPK3, 5'-GCA CTC CTC AGA TTC CAC ATA C-3' (sense) and 5'-GTG TCT TCC ATC TCC CTG ATT C-3' (antisense).

\section{Statistical analysis}

Statistical analysis was performed using the nonparametric Mann-Whitney $U$ test for comparisons of two groups, and one-way analysis of variance with the Bonferroni post hoc test for multiple groups. Prism ver. 5.01 software (GraphPad Software Inc., San Diego, CA, USA) was used. $P<0.05$ was regarded as the threshold for statistical significance. Data are presented as means \pm standard deviations.

\section{Results}

Effect of $L$. sakei on helper T cell differentiation and cytokine production

To evaluate the effects of $L$. sakei on $\mathrm{CD}^{+} \mathrm{T}$ cell differentiation and cytokine production, splenocytes from C57BL/6 mice were cultured with vehicle (control) or L. sakei $(1 \mu \mathrm{g} / \mathrm{mL})$. The Th17 population $\left(\mathrm{IL}-17^{+} \mathrm{CD} 4^{+}\right.$ $\mathrm{T}$ cells) and the IL-17 level in culture supernatant were significantly reduced by exposure to $L$. sakei (Fig. 1a, b). In the L. sakei-treated group, the Treg (Foxp $3^{+} \mathrm{CD} 25^{\text {high }} \mathrm{CD} 4{ }^{+} \mathrm{T}$ cells) population was suppressed, whereas the IL-10 level was increased (Fig. 1c, d). The Th17 population and IL-17 level were suppressed by exposure to L. sakei; however, the IL-10 level was increased. 

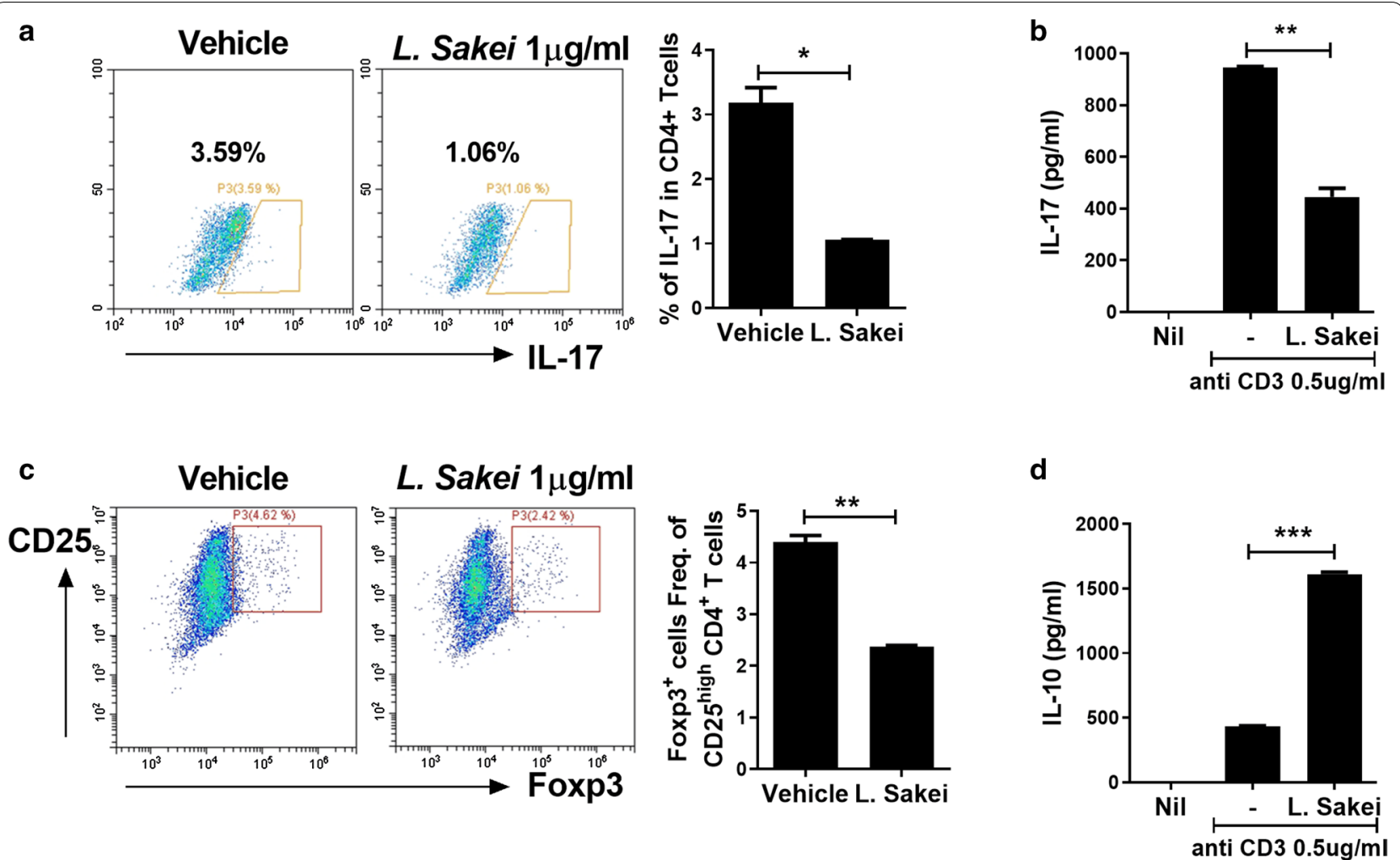

Fig. 1 L. sakei suppresses Th17 differentiation and IL-17 expression in mouse splenocytes. a C57bl/6 splenocytes were cultured with an anti-CD3 antibody for $72 \mathrm{~h}$ and the resulting $\mathrm{CD} 4^{+} \mathrm{IL}-17^{+}$and $\mathrm{CD} 4^{+} \mathrm{CD} 25^{\text {high }}$ Foxp $3^{+}$cells were enumerated. $\mathbf{b} \mathrm{IL}-17$ and $\mathrm{IL}-10$ levels in culture supernatant measured by ELISA. Data are means \pm standard deviations from three independent experiments $\left({ }^{*} \mathrm{P}<0.05,{ }^{* *} \mathrm{P}<0.03,{ }^{* * *} \mathrm{P}<0.01\right)$

To evaluate the effects of $L$. sakei on the differentiation of human $\mathrm{CD} 4^{+} \mathrm{T}$ cells and identify the mechanism for increased levels of IL-10, we cultured human PBMCs in the presence of vehicle or $L$. sakei $(0.1$ or $1 \mu \mathrm{g} /$ $\mathrm{mL}$ ). Exposure to $L$. sakei reduced the Th17 population in a dose-dependent manner, whereas the Treg population was unaffected (Fig. 2a). Exposure to L. sakei also reduced the IL-17 level and increased the level of IL-10 (Fig. 2b). Furthermore, treatments with 1 or $10 \mu \mathrm{g} / \mathrm{mL} L$. sakei resulted in an increased Breg population, compared to the control (Fig. 2c). Therefore, we concluded that $L$. sakei exerts an immunomodulatory effect by altering the populations of Th17 and Breg cells, as well as the levels of IL-17 and IL-10.

\section{sakei-mediated inhibition of the development of CIA}

Oral administration of L. sakei RH1114 or RH1117 to CIA mice attenuated CIA, as evidenced by a significantly lower arthritis score compared to the control mice. Only L. sakei RH1117 significantly reduced the incidence of CIA (Fig. 3a). In mice that received $L$. $s a k e i$, the severity of arthritis was attenuated and cartilage preservation was enhanced, compared to the control mice (Fig. 3b). Furthermore, immunohistochemical staining of hind joints showed that administration of L. sakei reduced the levels of tumor necrosis factor- $\alpha$, IL-1 $\beta$, IL-6, and IL-17 (Fig. 3c). Flow cytometry analysis of splenocytes showed that the $\mathrm{Th} 17\left(\mathrm{IL} 17^{+} \mathrm{CD} 4^{+}\right.$ $\mathrm{T}$ cells) population was reduced by administration of L. sakei, whereas the populations of Th1 (IFN$\mathrm{r}^{+} \mathrm{CD} 4^{+} \mathrm{T}$ cells), Th2 (IL- $4^{+} \mathrm{CD} 4^{+} \mathrm{T}$ cells), and Tregs (Foxp $3^{+} \mathrm{CD} 25^{+} \mathrm{CD} 4^{+} \mathrm{T}$ cells) did not differ significantly between $L$. sakei- and vehicle-treated mice with CIA (Fig. 4).

\section{Effects of $L$. sakei on osteoclastogenesis}

TRAP-positive multinucleated cells containing three or more nuclei were regarded as osteoclasts. L. sakei reduced the numbers of TRAP-, RANK-, and RANKLpositive cells in mice with CIA. The numbers of TRAP ${ }^{+}$ multinucleated cells were significantly lower in mice that received 1 or $10 \mu \mathrm{g} / \mathrm{mL}$ L. sakei (Fig. 5a). Similarly, the expression levels of osteoclast-related genes (TRAP and calcitonin receptor) were reduced by administration of 1 or $10 \mu \mathrm{g} / \mathrm{mL} \mathrm{L}$. sakei (Fig. 5b). The expression of cathep$\sin \mathrm{K}$ was significantly reduced only by administration of $1 \mu \mathrm{g} / \mathrm{mL}$ L. sakei. 

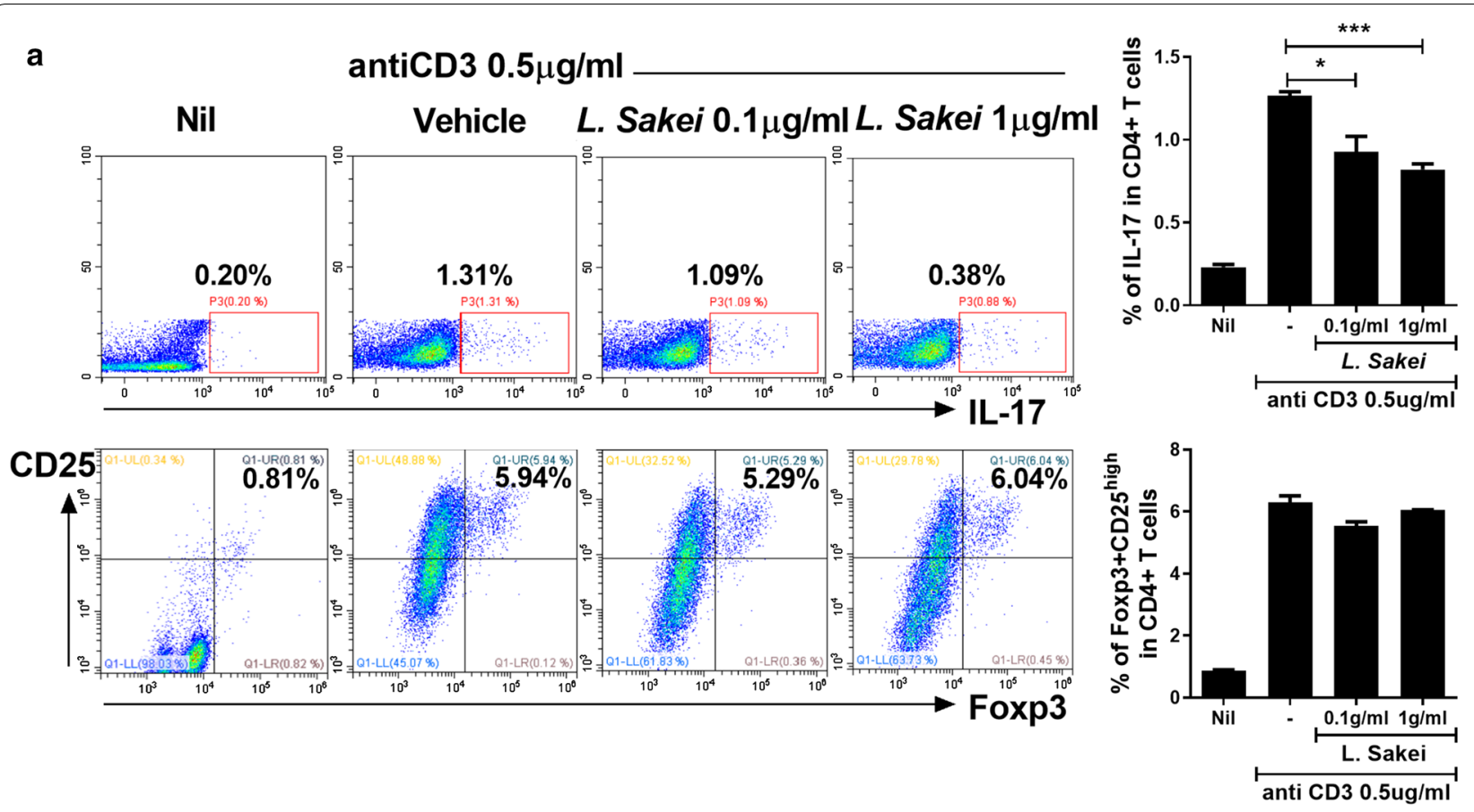

b
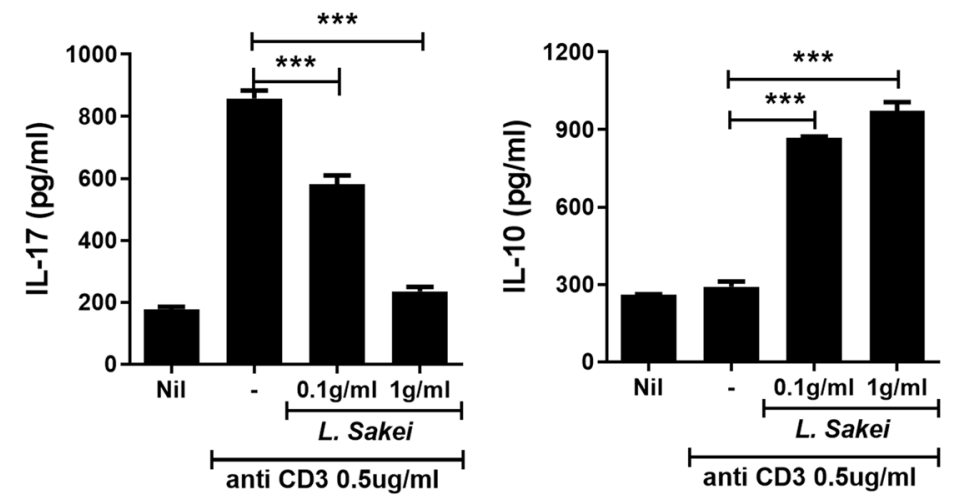

C

LPS 100ng/ml

Vehicle

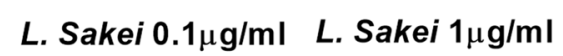

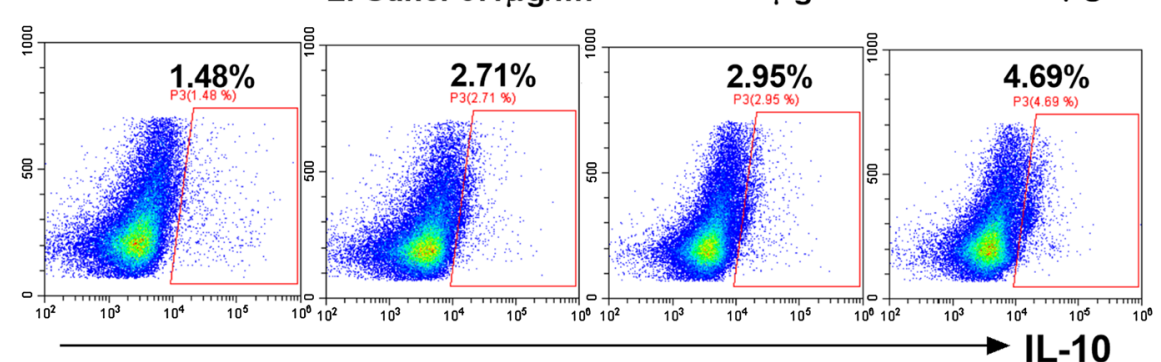

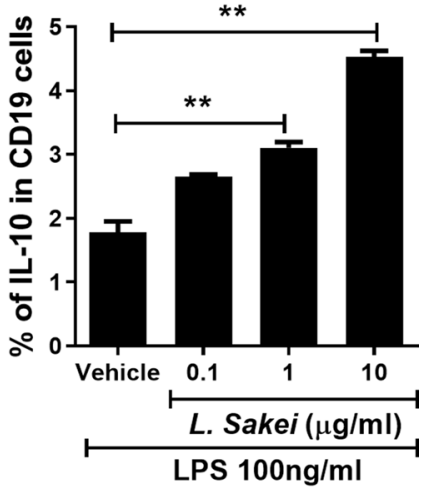

Fig. 2 L. sakei increases the IL-10 level and reduces the Th17 population and IL-17 expression in human PBMCs. a Normal human PBMCs were cultured with an anti-CD3 antibody for $72 \mathrm{~h}$ and the resulting $\mathrm{CD} 4^{+} \mathrm{IL}-17^{+}$and $\mathrm{CD} 4^{+} \mathrm{CD} 25^{\text {high }}$ Foxp $3^{+}$cells were enumerated. $\mathbf{b} \mathrm{IL}-17$ and IL-10 levels in culture supernatant measured by ELISA. c Normal human PBMCs were cultured in the presence of lipopolysaccharide for $72 \mathrm{~h}$ and the resulting $\mathrm{CD} 19^{+} \mathrm{IL}-10^{+}$cells were enumerated. Data are means \pm standard deviations from three independent experiments $\left({ }^{*} \mathrm{P}<0.05,{ }^{* *} \mathrm{P}<0.03\right.$, $\left.{ }^{* * *} \mathrm{P}<0.01\right)$ 
(See figure on next page.)

Fig. 3 L. sakei RH1 114 and RH1117 inhibit the development of RA in a mouse model. a L. sakei $(50 \mathrm{mg} / \mathrm{kg})(\mathrm{n}=5)$ was fed orally once per day to DBA/1 J mice with CIA. Left, arthritis score; right, arthritis incidence. $\mathbf{b}$ Effect of $L$. sakei on RA in mice with CIA. Tissue from the hind-paw joints was stained with hematoxylin and eosin, as well as Safranin O. c Immunohistochemical analysis showed that L. sakei ameliorated CIA and downregulated proinflammatory factors, compared to vehicle (control). Immunohistochemical staining for tumor necrosis factor- $\alpha$, IL-1 $\beta$, IL-6, and IL-17 in the synovium of mice with CIA (scale bar, $100 \mu \mathrm{m})\left({ }^{*} \mathrm{P}<0.05,{ }^{* *} \mathrm{P}<0.03,{ }^{* * *} \mathrm{P}<0.01\right)$

\section{Discussion}

This is the first report of the anti-inflammatory and immunomodulatory activity of $L$. sakei in a mouse model of RA. Administration of L. sakei altered the IL-17/IL-10 balance by regulating the Th17 and Breg populations, but not the Treg population. In addition, oral administration of $L$. sakei reduced the incidence and severity of arthritis and suppressed osteoclastogenesis.

Disruption of normal-flora homeostasis (i.e., dysbiosis) has important immunologic sequalae. In health, the host-microbiome interaction maintains homeostasis. However, dysbiosis has been implicated in several autoimmune diseases [4]. In patients with RA, periodontitis caused by $P$. gingivalis is reportedly associated with the production of anti-citrullinated protein antibodies [30]; moreover, 16S rRNA sequencing of gut microbiota showed an increased population of Prevotella copri in these patients [18, 31]. Furthermore, P. copri isolated from patients with RA induced the differentiation of Th17 cells [31]. These results indicate a role for the microbiome in the onset of RA. In this study, L. sakei modulated the Th17 and Breg populations and attenuated arthritis in mice with CIA. Therefore, administration of $L$. sakei has therapeutic potential for RA.

Proinflammatory cytokines and their source cells are implicated in the pathogenesis of RA; thus, modulation of these cytokines and cells is a target of treatment for RA [20]. Suppression of the inflammatory response with concurrent enhancement of the anti-inflammatory response is the ideal therapeutic approach for patients with autoimmune diseases. Patients with RA have an increased population of Th17 cells and an elevated serum level of IL-17 [32, 33]; modulation of these components has been reported to exert beneficial effects in several animal models of RA [34,35]. In the context of RA, B cells and plasma cells were previously considered to be limited to the production of autoantibodies, such as anti-rheumatoid factor and anti-citrullinated protein antibodies. However, Bregs also produce anti-inflammatory cytokines and suppress the expansion of pathogenic $T$ cells [25]. In patients with RA, the numbers and activities of IL-10-producing Bregs are reduced, compared to healthy controls [36]. In addition, targeting proinflammatory cytokines, such as TNF- $\alpha$ and IL-6, have shown clinical improvement in RA patients [20], and our results showed decrement of these cytokines in affected joints. In the present study, administration of $L$. sakei reduced pathologic cytokines in peripheral joints of CIA animal, and the population of Th17 cells and serum level of IL-17, whereas increased the population of Breg cells and serum level of IL-10.

Difference in composition of gut microbiome in RA is well known, and even disease-modifying antirheumatic drug can change the functional potency of microbiome. We hypothesized that same bacterium species may have different potential on anti-inflammatory effect according to disease status. In present study, the $L$. sakei RH1114 (from RA patients) did not show overall decrease in arthritis incidence in CIA model, whereas L. sakei RH1117 (from healthy control) showed obvious decline in arthritis incidence. Present study showed the functional difference between $L$. sakei from healthy donor and RA patients in animal model, and further study implicating these differences in human study may clarify the functional difference of $L$. sakei depending on the source.

Probiotics have fewer side effects than conventional or biologic disease-modifying antirheumatic drugs, because they aim to restore the normal microbial environment and immune system. L. sakei has been reported to exert beneficial effects on several inflammatory disorders such as colitis, atopic dermatitis, chronic rhinosinusitis, and obesity [13-15, 37]. Although the preventive effect of $L$. sakei on CIA was smaller than that of methotrexate, it was greater than the effect of vehicle. Increased osteoclastogenesis promotes joint destruction and early onset osteoporosis in patients with RA [20]. Treatment of early onset osteoporosis is important in these patients, because their chronic inflammatory status (due to long-term use of glucocorticoids) can exacerbate osteoporosis [38]. Osteoclasts are the main effector cells in osteoporosis, and a therapeutic modality that acts on both arthritis and osteoporosis would likely be effective for patients RA. In this context, oral administration of $L$. sakei in combination with conventional/biologic disease-modifying antirheumatic drug therapy is promising. However, translational study on human (established RA and high-risk population for RA) could clarify the therapeutic and preventive effect of L. sakei in real RA patients. 
a
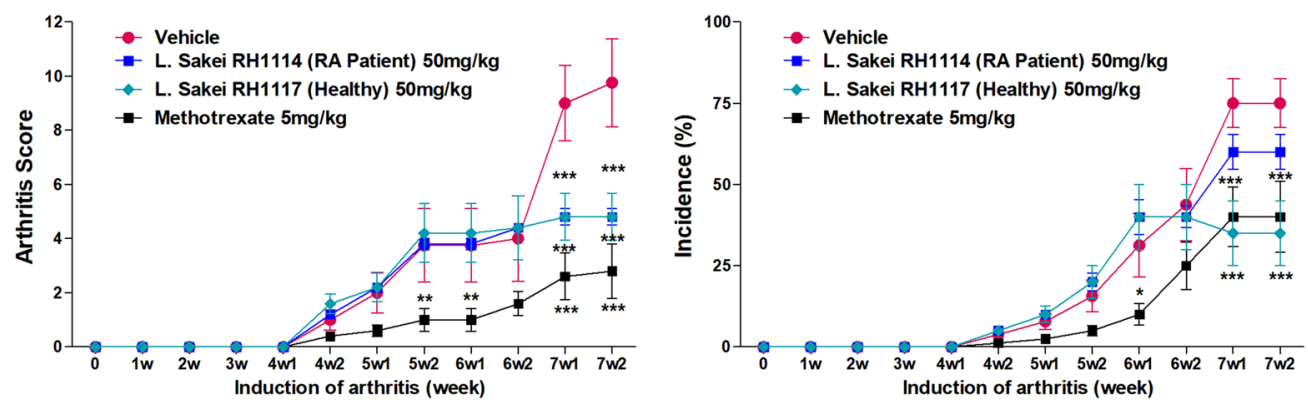

b

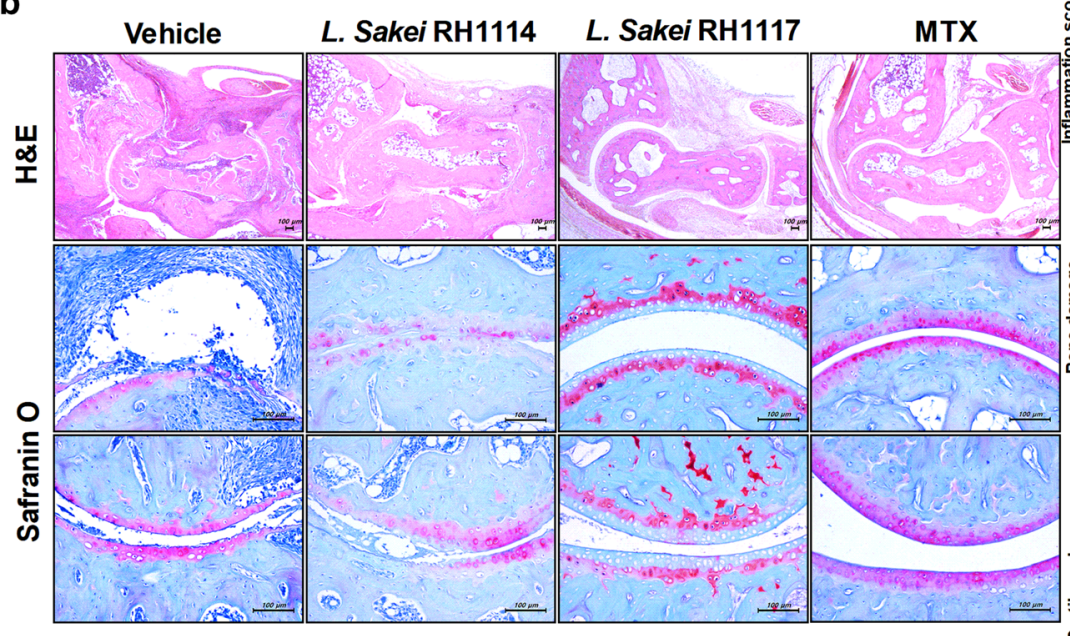

C

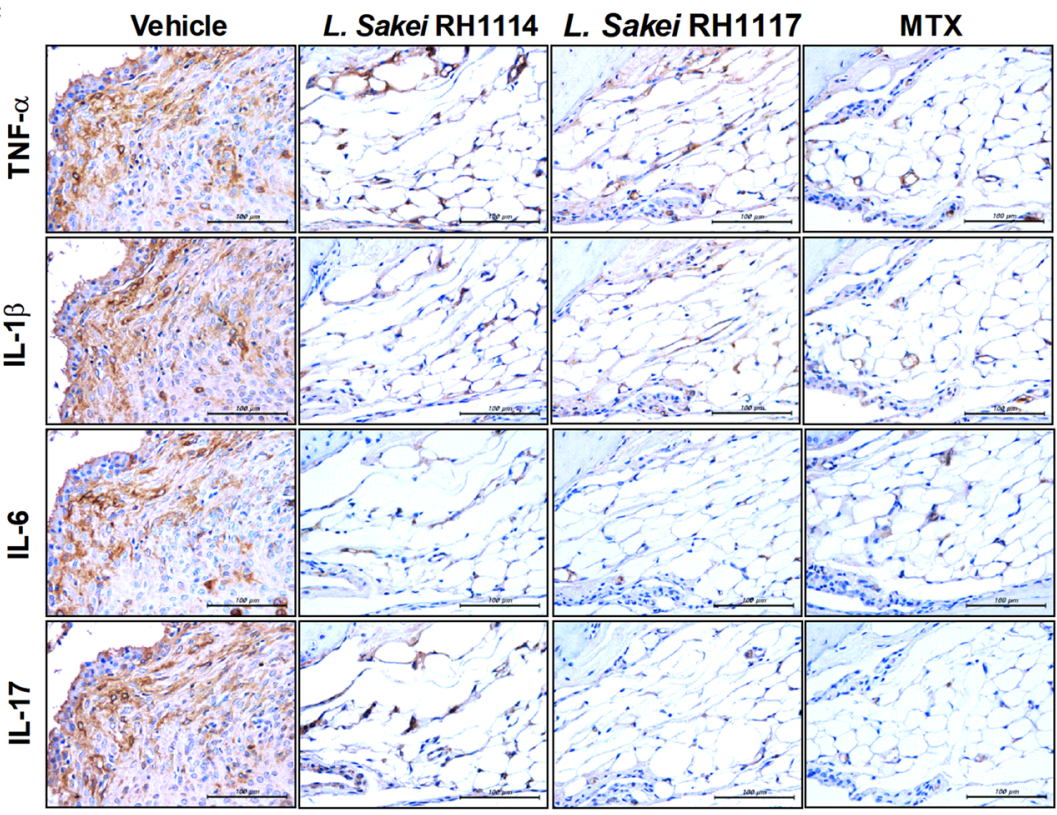

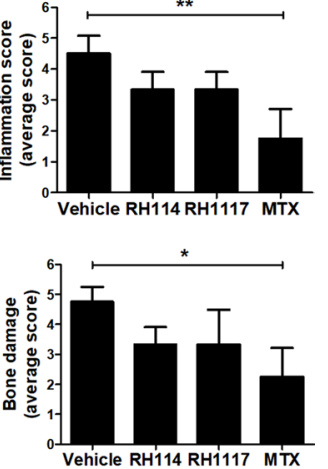
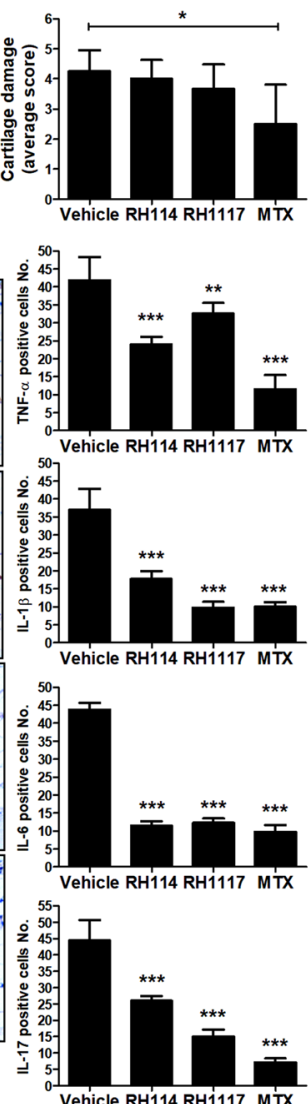


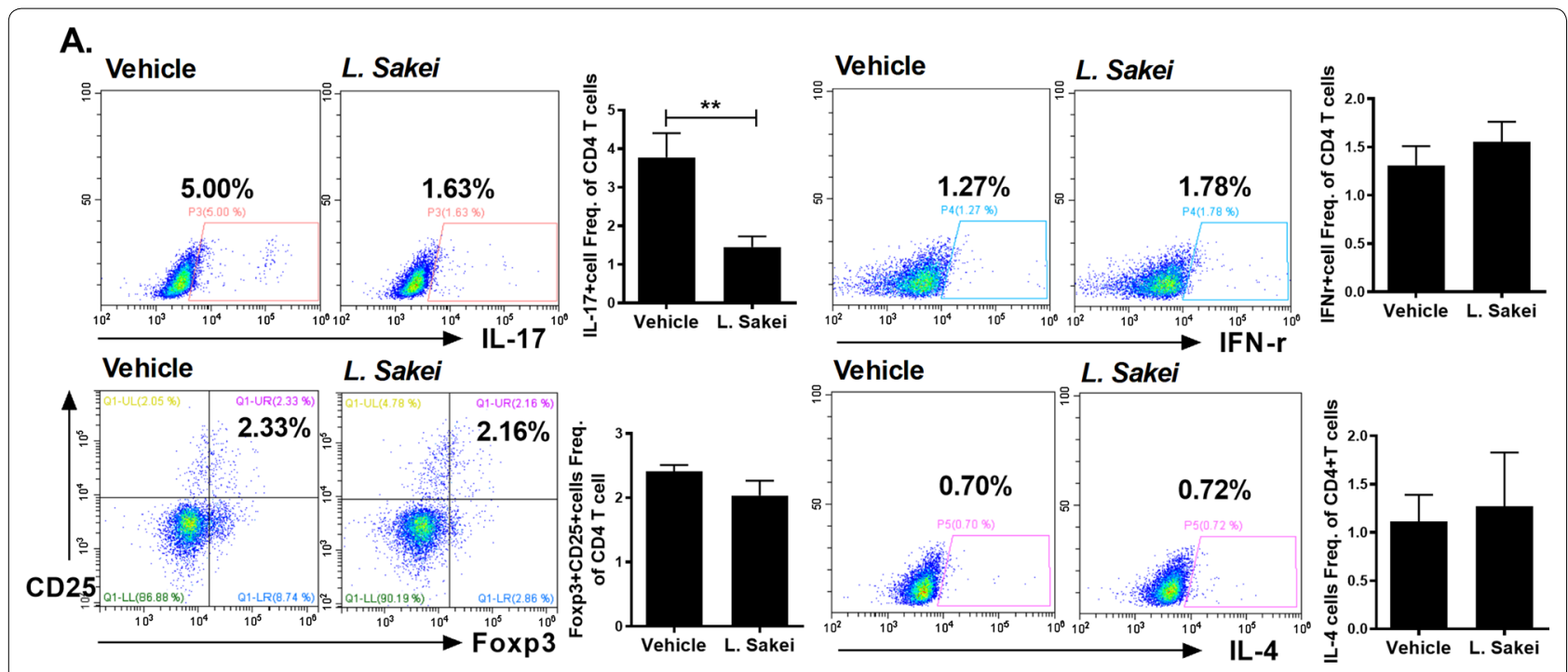

Fig. 4 L. sakei reduces IL-17 expression but maintains expression of Foxp3 in CD4 ${ }^{+} \mathrm{T}$ cells from the spleen of mice with CIA. a. Flow cytometry of Th1 cells $\left(\mathrm{IFN}-\mathrm{r}^{+} \mathrm{CD} 4^{+}\right)$, Th2 cells $\left(\mathrm{IL}-4^{+} \mathrm{CD} 4^{+}\right)$, Th17 cells $\left(\mathrm{CD} 4^{+} \mathrm{IL} 17^{+}\right)$, and Tregs (Foxp $\left.3^{+} \mathrm{CD} 25^{+} \mathrm{CD} 4^{+}\right)$from the spleen of mice with $\mathrm{ClA}$
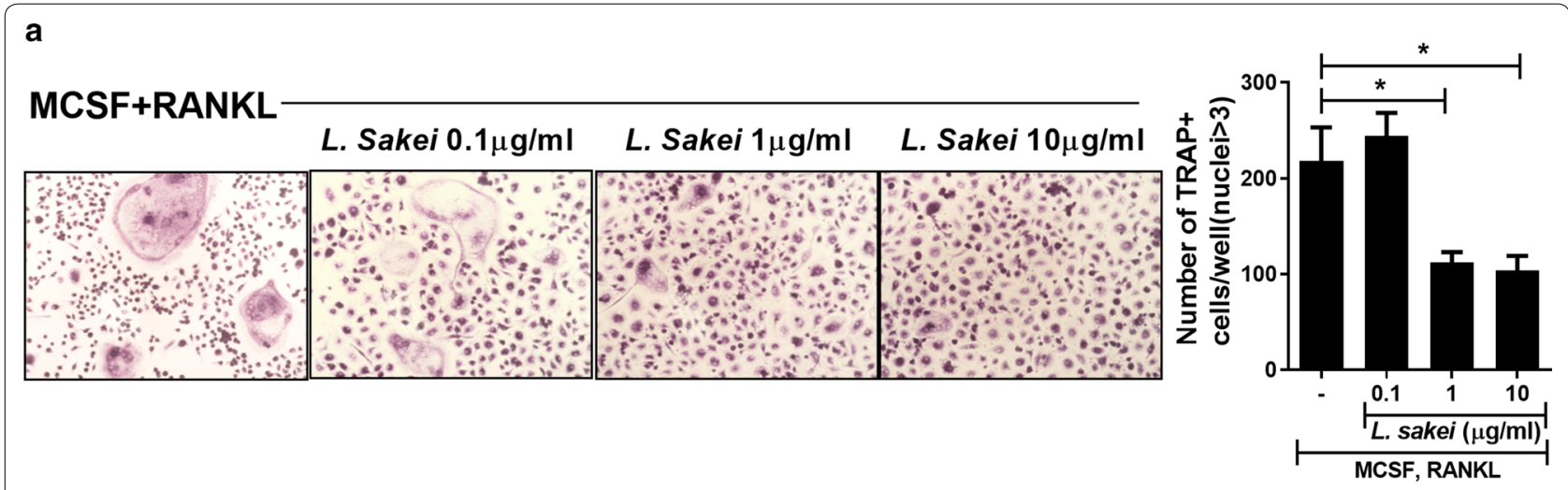

b
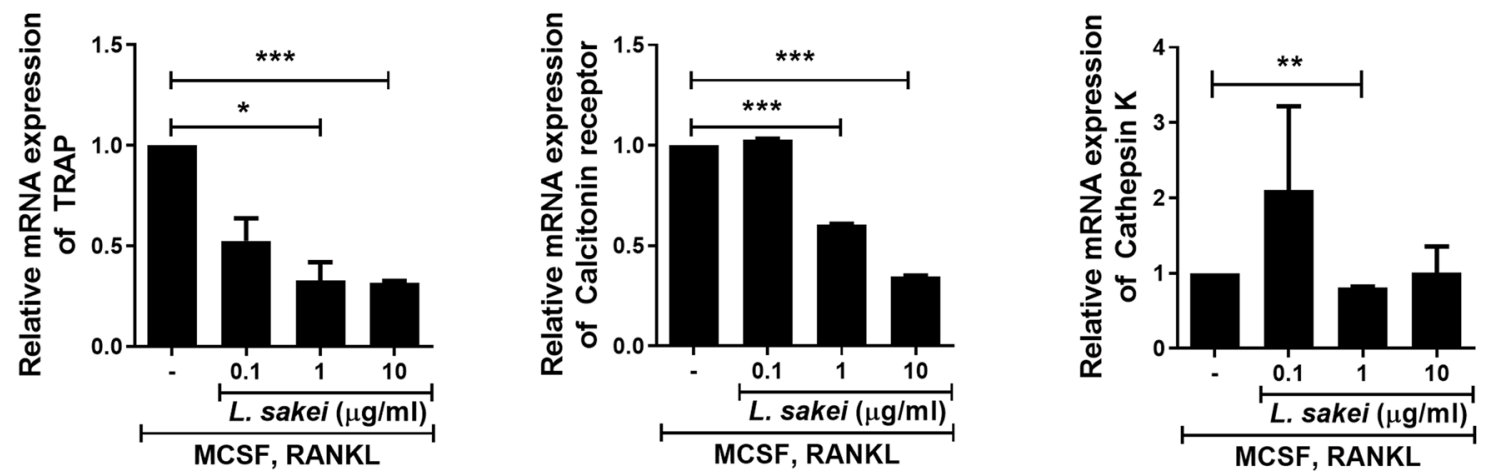

Fig. 5 L. sakei inhibits osteoclastogenesis. a Suppression of TRAP in the ankle joints of $L$. sakei-treated mice with autoimmune arthritis at 7 weeks, demonstrated by immunohistochemical staining. b TRAP staining of human monocytes cultured with $25 \mathrm{ng} / \mathrm{mL}$ macrophage colony-stimulating factor and $30 \mathrm{ng} / \mathrm{mL}$ RANKL in the presence or absence of L. sakei for 9 days. $\mathbf{c}$ mRNA levels of TRAP, calcitonin receptor, and cathepsin $\mathrm{K}$ assessed by real-time polymerase chain reaction and normalized to the level of $\beta$-actin. Bars indicate means \pm standard errors of the mean ${ }^{*} P<0.05$, ${ }^{* *} P<0.03$, ***P $<0.01$ ) 


\section{Conclusion}

This study showed that administration of L. sakei exerted a beneficial effect in an animal model of RA. Furthermore, L. sakei skewed the Th17 and Breg populations towards an anti-inflammatory phenotype and suppressed osteoclastogenesis. Therefore, L. sakei has therapeutic potential for RA.

\section{Abbreviations}

CIA: Collagen induced arthritis; RA: Rheumatoid arthritis; IL: Interleukine; Treg: T regulatory; TRAP: Tartrate-resistant acid phosphatase; RANK: Receptor activator of nuclear factor kappa-B; RANKL: RANK ligand; M-CSF: Macrophage colony-stimulating factor.

\section{Acknowledgements}

None.

\begin{abstract}
Authors' contributions
JYJ, HKM participated in the study design and data interpretation. JYJ, HKM participated writing the manuscript. JYR, SYL, JYK, JGR, JWC and SYL carried out the animal experiments, acquired the data and performed the statistical analysis. YJJ, SJP, MSP, BK, GEJ participated in the study design and data interpretation. MLC and SHP conceived and designed the study, interpreted the data, and made critical revisions of the manuscript for important intellectual content. All authors read and approved the final manuscript.
\end{abstract}

\section{Funding}

This research was supported by the Bio \& Medical Technology Development Program of the National Research Foundation (NRF) \& funded by the Korean Government (MSIT) (No. NRF-2017M3A9F3041045).

\section{Availability of data and materials}

All data are available in the manuscript or upon request to the authors.

\section{Ethics approval and consent to participate}

All experimental procedures were approved by the Department of Laboratory Animals, Institutional Animal Care and Use Committee (IACUC) of the School of Medicine, the Catholic University of Korea and conformed with all National Institutes of Health (USA) guidelines (Permit Number: CUMC 2019-0242-01).

\section{Consent for publication}

Not applicable.

\section{Competing interests}

The authors declare that they have no competing interests.

\section{Author details}

${ }^{1}$ Rheumatism Research Center, Catholic Research Institute of Medical Science, College of Medicine, The Catholic University of Korea, Seoul 06591, South Korea. ${ }^{2}$ Laboratory of Immune Network, Catholic Research Institute of Medical Science, College of Medicine, College of Medicine, The Catholic University of Korea, Seoul, Republic of Korea. ${ }^{3}$ Division of Rheumatology, Department of Internal Medicine, Konkuk University Medical Center, Seoul, Republic of Korea. ${ }^{4}$ Research center, BIFIDO Co., Ltd., Hongcheon, Gangwon-do, Republic of Korea. ${ }^{5}$ Department of Food and Nutrition, Research Institute of Human Ecology, Seoul National University, Seoul, Republic of Korea. ${ }^{6}$ Department of Medical Lifescience, College of Medicine, The Catholic University of Korea, 222, Banpo-daero, Seocho-gu, Seoul 06591, Republic of Korea. ${ }^{7}$ Devision of Rheumatology, Department of Internal Medicine, Seoul St. Mary's Hospital, College of Medicine, The Catholic University of Korea, Seoul, Republic of Korea.

Received: 9 March 2020 Accepted: 2 August 2020

Published online: 15 August 2020

\section{References}

1. Tobon GJ, Youinou P, Saraux A. The environment, geo-epidemiology, and autoimmune disease: rheumatoid arthritis. J Autoimmun. 2010;35:10-4.

2. Hunter TM, Boytsov NN, Zhang X, Schroeder K, Michaud K, Araujo AB. Prevalence of rheumatoid arthritis in the United States adult population in healthcare claims databases, 2004-2014. Rheumatol Int. 2017:37:1551-7.

3. Smolen JS, Aletaha D, Barton A, Burmester GR, Emery P, Firestein GS, et al. Rheumatoid arthritis. Nat Rev Dis Primers. 2018:4:18001.

4. Belkaid $Y$, Hand TW. Role of the microbiota in immunity and inflammation. Cell. 2014;157:121-41.

5. Mikuls TR, Payne JB, Yu F, Thiele GM, Reynolds RJ, Cannon GW, et al. Periodontitis and porphyromonas gingivalis in patients with rheumatoid arthritis. Arthritis Rheumatol. 2014;66:1090-100.

6. Brusca SB, Abramson SB, Scher JU. Microbiome and mucosal inflammation as extra-articular triggers for rheumatoid arthritis and autoimmunity. Curr Opin Rheumatol. 2014;26:101-7.

7. du Teil Espina M, Gabarrini G, Harmsen HJM, Westra J, van Winkelhoff AJ, van Dijl JM. Talk to your gut: the oral-gut microbiome axis and its immunomodulatory role in the etiology of rheumatoid arthritis. FEMS Microbiol Rev. 2019;43:1-18.

8. Mohammed AT, Khattab M, Ahmed AM, Turk T, Sakr N, Khalil AM, et al. The therapeutic effect of probiotics on rheumatoid arthritis: a systematic review and meta-analysis of randomized control trials. Clin Rheumatol. 2017;36:2697-707.

9. Yamashita M, Matsumoto K, Endo T, Ukibe K, Hosoya T, Matsubara Y, et al. Preventive effect of lactobacillus helveticus SBT2171 on collagen-induced arthritis in mice. Front Microbiol. 2017;8:1159.

10. Lee SY, Lee SH, Jhun J, Seo HB, Jung KA, Yang CW, et al. A combination with probiotic complex, zinc, and coenzyme Q10 attenuates autoimmune arthritis by regulation of Th17/Treg balance. J Med Food. 2018;21:39-46

11. Esvaran M, Conway PL. Lactobacillus fermentum PC1 has the capacity to attenuate joint inflammation in collagen-induced arthritis in DBA/1 mice. Nutrients. 2019:11:785.

12. Bredholt S, Nesbakken T, Holck A. Industrial application of an antilisterial strain of Lactobacillus sakei as a protective culture and its effect on the sensory acceptability of cooked, sliced, vacuum-packaged meats. Int J Food Microbiol. 2001;66:191-6.

13. Jang SE, Min SW. Lactobacillus sakei S1 improves colitis induced by 2,4,6-trinitrobenzene sulfonic acid by the inhibition of NF-kappaB signaling in mice. J Microbiol Biotechnol. 2019;30(1):71-8.

14. Ji Y, Park S, Chung Y, Kim B, Park H, Huang E, et al. Amelioration of obesityrelated biomarkers by Lactobacillus sakei CJLS03 in a high-fat dietinduced obese murine model. Sci Rep. 2019;9:6821.

15. Abreu NA, Nagalingam NA, Song Y, Roediger FC, Pletcher SD, Goldberg AN, et al. Sinus microbiome diversity depletion and Corynebacterium tuberculostearicum enrichment mediates rhinosinusitis. Sci Transl Med. 2012:4:151ra24.

16. Yang E, Fan L, Jiang Y, Doucette $C$, Fillmore S. Antimicrobial activity of bacteriocin-producing lactic acid bacteria isolated from cheeses and yogurts. AMB Express. 2012;2:48.

17. Zagorec M, Champomier-Verges MC. Lactobacillus sakei: a starter for sausage fermentation, a protective culture for meat products. Microorganisms. 2017:5(3):56.

18. Scher JU, Sczesnak A, Longman RS, Segata N, Ubeda C, Bielski C, et al. Expansion of intestinal Prevotella copri correlates with enhanced susceptibility to arthritis. Elife. 2013;2:e01202.

19. Bodkhe R, Balakrishnan B, Taneja V. The role of microbiome in rheumatoid arthritis treatment. Adv Musculoskelet Dis. 2019. https://doi. org/10.1177/1759720X19844632.

20. Aletaha D, Smolen JS. Diagnosis and management of rheumatoid arthritis: a review. JAMA. 2018;320:1360-72.

21. Miossec P, Kolls JK. Targeting IL-17 and TH17 cells in chronic inflammation. Nat Rev Drug Discov. 2012;11:763-76.

22. Robert M, Miossec P. IL-17 in rheumatoid arthritis and precision medicine: from synovitis expression to circulating bioactive levels. Front Med. 2018:5:364.

23. Couper KN, Blount DG, Riley EM. IL-10: the master regulator of immunity to infection. J Immunol. 2008;180:5771-7. 
24. Lund FE. Cytokine-producing B lymphocytes-key regulators of immunity. Curr Opin Immunol. 2008;20:332-8.

25. Rosser EC, Mauri C. Regulatory B cells: origin, phenotype, and function. Immunity. 2015:42:607-12.

26. Ummarino D. Rheumatoid arthritis: defective IL-10-producing Breg cells Nat Rev Rheumatol. 2017;13:132.

27. Choudhary N, Bhatt LK, Prabhavalkar KS. Experimental animal models for rheumatoid arthritis. Immunopharmacol Immunotoxicol. 2018:40:193-200.

28. Barnett ML, Kremer JM, St Clair EW, Clegg DO, Furst D, Weisman M, et al. Treatment of rheumatoid arthritis with oral type II collagen Results of a multicenter, double-blind, placebo-controlled trial. Arthritis Rheum. 1998:41:290-7.

29. Aletaha D, Neogi T, Silman AJ, Funovits J, Felson DT, Bingham CO 3rd, et al. 2010 rheumatoid arthritis classification criteria: an American College of Rheumatology/European League Against Rheumatism collaborative initiative. Ann Rheum Dis. 2010;69:1580-8.

30. Wegner N, Wait R, Sroka A, Eick S, Nguyen KA, Lundberg K, et al. Peptidylarginine deiminase from Porphyromonas gingivalis citrullinates human fibrinogen and alpha-enolase: implications for autoimmunity in rheumatoid arthritis. Arthritis Rheum. 2010;62:2662-72.

31. Maeda Y, Kurakawa T, Umemoto E, Motooka D, Ito Y, Gotoh K, et al. Dysbiosis contributes to arthritis development via activation of autoreactive T cells in the intestine. Arthritis Rheumatol. 2016;68:2646-61.

32. Leipe J, Grunke M, Dechant C, Reindl C, Kerzendorf U, Schulze-Koops H, et al. Role of Th17 cells in human autoimmune arthritis. Arthritis Rheum. 2010;62:2876-85.
33. van Hamburg JP, Asmawidjaja PS, Davelaar N, Mus AM, Colin EM, Hazes $J M$, et al. Th17 cells, but not Th1 cells, from patients with early rheumatoid arthritis are potent inducers of matrix metalloproteinases and proinflammatory cytokines upon synovial fibroblast interaction, including autocrine interleukin-17A production. Arthritis Rheum. 2011;63:73-83.

34. Lee SY, Min HK, Lee SH, Shin HJ, Lee WY, Cho YG, et al. IL-1 receptor antagonist (IL-1Ra)-Fc ameliorate autoimmune arthritis by regulation of the Th17 cells/Treg balance and arthrogenic cytokine activation. Immunol Lett. 2016;172:56-66.

35. Jhun J, Lee SH, Byun JK, Jeong JH, Kim EK, Lee J, et al. Coenzyme Q10 suppresses Th17 cells and osteoclast differentiation and ameliorates experimental autoimmune arthritis mice. Immunol Lett. 2015;166:92-102.

36. Banko Z, Pozsgay J, Szili D, Toth M, Gati T, Nagy G, et al. Induction and differentiation of IL-10-producing regulatory B cells from healthy blood donors and rheumatoid arthritis patients. J Immunol. 2017;198:1512-20.

37. Kwon MS, Lim SK, Jang JY, Lee J, Park HK, Kim N, et al. Lactobacillus sakei WIKIM30 ameliorates atopic dermatitis-like skin lesions by inducing regulatory $T$ cells and altering gut microbiota structure in mice. Front Immunol. 2018;9:1905.

38. Dougados M. Comorbidities in rheumatoid arthritis. Curr Opin Rheumatol. 2016;28:282-8.

\section{Publisher's Note}

Springer Nature remains neutral with regard to jurisdictional claims in published maps and institutional affiliations.
Ready to submit your research? Choose BMC and benefit from:

- fast, convenient online submission

- thorough peer review by experienced researchers in your field

- rapid publication on acceptance

- support for research data, including large and complex data types

- gold Open Access which fosters wider collaboration and increased citations

- maximum visibility for your research: over $100 \mathrm{M}$ website views per year

At BMC, research is always in progress.

Learn more biomedcentral.com/submissions 